\title{
Acute Pyelonephritis
}

National Cancer Institute

\section{Source}

National Cancer Institute. Acute Pyelonephritis. NCI Thesaurus. Code C123215.

Sudden onset pyelonephritis. 